\title{
Correction to: Nutritional Metabolomics in Cancer Epidemiology: Current Trends, Challenges, and Future Directions
}

\author{
Emma E. McGee ${ }^{1,2} \cdot$ Rama Kiblawi $^{3} \cdot$ Mary C. Playdon $^{3,4} \cdot$ A. Heather Eliassen ${ }^{1,2}$
}

Published online: 13 June 2019

(C) Springer Science+Business Media, LLC, part of Springer Nature 2019

\section{Correction to: Curr Nutr Rep https://doi.org/10.1007/s13668-019-00279-z}

The article was published with errors on text as the author's corrections were misinterpreted.

These two words "However, although" must be deleted at the phrase "However, although Dietary guidelines for cancer prevention are available..." to read "Dietary guidelines for cancer prevention are available...".

Also the word "collaboration" must be inserted back after "international" at a phrase within "Future Directions" section to read "...international collaboration comprised of more than 50 prospective cohorts...".

The original article has been corrected.

Publisher's Note Springer Nature remains neutral with regard to jurisdictional claims in published maps and institutional affiliations.

The online version of the original article can be found at https://doi.org/ $10.1007 / \mathrm{s} 13668-019-00279-\mathrm{z}$

Emma E. McGee

emcgee@hsph.harvard.edu

1 Channing Division of Network Medicine, Department of Medicine, Brigham and Women's Hospital, Harvard Medical School,

Boston, MA, USA

2 Department of Epidemiology, Harvard T.H. Chan School of Public Health, Boston, MA, USA

3 Division of Cancer Population Sciences, Huntsman Cancer Institute, University of Utah, Salt Lake City, UT, USA

4 Department of Nutrition and Integrative Physiology, University of Utah, Salt Lake City, UT, USA 